\title{
Handlanger, Kollegen, Konkurrenten?
}

\section{Liebe Leserinnen und Leser,}

wenn man Diskussionen über die Auswirkungen der Digitalisierung verfolgt, spürt man häufig die Angst davor, dass sie Heerscharen von Menschen arbeitslos machen wird - und das nicht nur im Bereich einfacher Tätigkeiten, sondern auch im Feld von Berufen, die einen hohen Ausbildungsstand benötigen, wie etwa Medizinern oder Juristen. Entsprechende Diskussionen haben nun auch das Controlling erreicht. Wird es aufgrund von Automatisierung und Robotisierung bald keine Controller mehr geben? Angst ist aber ein schlechter Ratgeber, ein differenzierter Blick erforderlich. Machen wir uns die Entwicklung anhand der drei anschaulichen Begriffe Handlanger, Kollegen und Konkurrenten deutlich.

Die Digitalisierung mit all ihren Möglichkeiten hilft als Handlanger den Controllern sehr, ihren Job noch besser zu machen: schneller, weniger fehlerbehaftet, tiefer gehend, umfassender und effizienter. Dies betrifft insbesondere transaktionale Standardtätigkeiten. Sie machen nur wenigen Controllern Spaß. „Bots“, wie Software-Roboter kurz genannt werden, können diese Aufgaben fehlerfrei und quasi aufwandslos übernehmen. Hiermit werden Kapazitäten von Controllern freigesetzt. Die Unternehmen können entscheiden, ob sie diese in Aufgaben investieren, die mehr eigene Expertise und eigenes Denken der Controller erfordern, oder ob ControllerStellen wegfallen.

Neue Instrumente im Kontext der Digitalisierung können daneben zu einer kollegialen Zusammenarbeit zwischen Mensch und Maschine führen. Ein gutes Beispiel dafür ist die Mustererkennung innerhalb von Datenbeständen, das Erkennen von sinnhaften Zusammenhängen, die neue unternehmerische Handlungsoptionen eröffnen. Controller können die Fähigkeit der Maschine zum einen nutzen, um vorab erarbeitete Hypothesen empirisch zu testen. Zum anderen kann die Maschine selbstständig Muster erkennen, die Controller dann auf ihren ökonomischen Sinn hinterfragen. Hier stellt sich unter anderem die Frage, ob Controller für diese Zusammenarbeit gerüstet sind oder ob andere Player, zum Beispiel Data Scientists, an ihre Stelle treten.

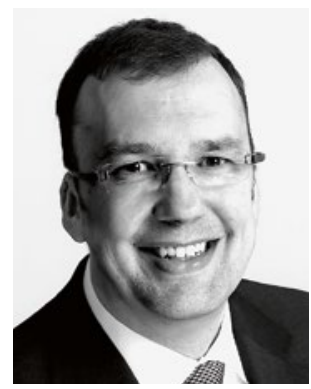

Utz Schäffer

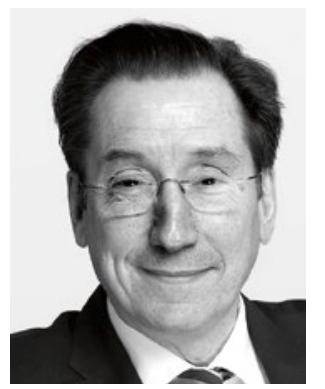

Jürgen Weber

Aber nicht nur diese, sondern auch die Maschinen selbst werden zu Konkurrenten, wenn sie losgelöst von Menschen komplexe Probleme intelligent lösen („Künstliche Intelligenz") und damit Menschen in ihrer bisherigen Domäne ersetzen können. Erste Ansätze dafür findet man schon in Unternehmen, wenn Programme beispielsweise in der Lage sind, sich selbst Informationen zu suchen und diese Suche bei einem zufriedenstellenden Niveau abzubrechen. Obwohl der Weg noch weit ist, erwächst für Controller hier in der Tat Konkurrenz: Warum soll die Maschine nicht den neutralen Drittblick übernehmen?

Was können wir Ihnen nach dieser kurzen Analyse raten? Sie sollten das Handlangerpotenzial der Digitalisierung möglichst schnell für sich erschließen. Sie sollten weiterhin versuchen, sich auf eine enge Partnerschaft mit der Maschine einzurichten. Sie durch die Maschine zu ersetzen, wird zwar noch etwas dauern. Einen Platz auf Ihrer strategischen Agenda hat aber auch dieses Thema verdient. Heute!

Viel Spaß bei der Lektüre wünschen Ihnen

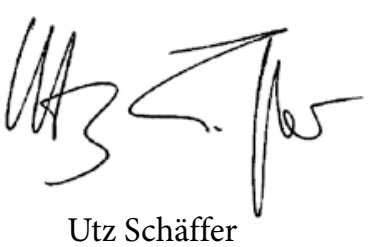

Utz Schäffer

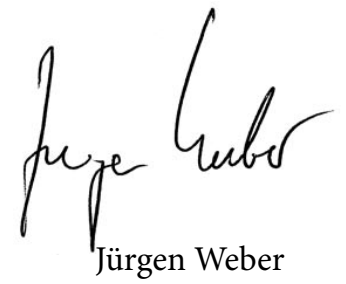

